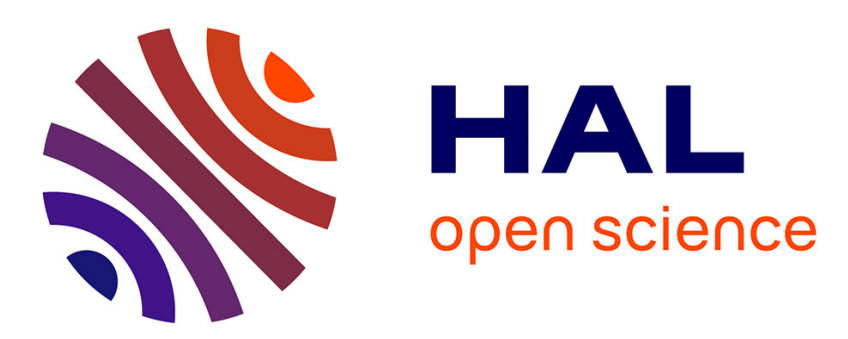

\title{
Expert opinion on the management of renal manifestations of chronic $\mathrm{HCV}$ infection
}

Fabrizio Fabrizi, Francesco Negro, Mark Bondin, Patrice Cacoub

\section{To cite this version:}

Fabrizio Fabrizi, Francesco Negro, Mark Bondin, Patrice Cacoub. Expert opinion on the management of renal manifestations of chronic HCV infection. Antiviral Therapy, 2018, 23 (Suppl 2), pp.57-67. 10.3851/IMP3247 . hal-01981546

\section{HAL Id: hal-01981546 https://hal.sorbonne-universite.fr/hal-01981546}

Submitted on 15 Jan 2019

HAL is a multi-disciplinary open access archive for the deposit and dissemination of scientific research documents, whether they are published or not. The documents may come from teaching and research institutions in France or abroad, or from public or private research centers.
L'archive ouverte pluridisciplinaire HAL, est destinée au dépôt et à la diffusion de documents scientifiques de niveau recherche, publiés ou non, émanant des établissements d'enseignement et de recherche français ou étrangers, des laboratoires publics ou privés. 


\title{
Expert opinion on the management of renal manifestations of chronic HCV infection
}

\author{
Fabrizio Fabrizi ${ }^{1}$, Francesco Negro ${ }^{2}$, Mark Bondin $^{3}$, Patrice Cacoub ${ }^{4,5,6,7, *}$ \\ ${ }^{1}$ Division of Nephrology, Maggiore Hospital and IRCCS Foundation, Milan, Italy \\ ${ }^{2}$ Divisions of Gastroenterology, Hepatology and Clinical Pathology, University Hospital, \\ Geneva, Switzerland \\ ${ }^{3}$ AbbVie Inc., Chicago, IL, USA \\ ${ }^{4}$ Sorbonne Universités, UPMC Univ Paris 06, UMR 7211, and Inflammation- \\ Immunopathology-Biotherapy Department (DHU i2B), Paris, France \\ ${ }^{5}$ INSERM, UMR_S 959, Paris, France \\ ${ }^{6}$ CNRS, FRE3632, F-75005, Paris, France \\ ${ }^{7}$ AP-HP, Groupe Hospitalier Pitié-Salpêtrière, Department of Internal Medicine and Clinical \\ Immunology, Paris, France
}

*Corresponding author e-mail: patrice.cacoub@aphp.fr

\section{Abstract}

Chronic HCV infection is a non-traditional (but modifiable) risk factor for chronic kidney disease and has been implicated in glomerular injury and nephrosclerotic disease. Three HCV direct-acting antiviral regimens are available for patients with severe kidney impairment: ombitasvir, paritaprevir with the pharmacokinetic enhancer ritonavir, and dasabuvir; glecaprevir plus pibrentasvir; and elbasvir plus grazoprevir. In patients with severe kidney impairment, sofosbuvir-free regimens are preferred because sofosbuvir accumulation has been associated with a progressive worsening of renal function. In this Review, we provide our expert opinion on the current HCV treatment paradigm and highlight the remaining issues that need to be overcome to improve the treatment of $\mathrm{HCV}$ in this population.

\section{Introduction}

$\mathrm{HCV}$ infection is endemic worldwide, with an estimated prevalence of $1 \%$ (approximately 71 million viraemic infections) [1]. HCV is implicated in the perturbation of multiple organ systems including the ocular, skeletal, nervous, cardiovascular and lymphatic systems and the skin [2]. In addition, HCV has been shown to cause metabolic alterations (insulin resistance and diabetes mellitus) [3] and has a deleterious impact on quality of life and psychosocial status $[4,5]$. Chronic kidney disease (CKD) affects $11.5 \%$ of the population in the USA and over $47 \%$ of individuals older than 70 years; reports from other countries are, in the main, consistent with these figures [6]. Recent data emphasized the rising prevalence of CKD in the general population, which is related to the rising epidemic of risk factors such as obesity, diabetes mellitus, arterial hypertension, smoking and ageing [7]. The high morbidity, mortality and health-care costs associated with CKD have led investigators to search for nontraditional risk factors such as chronic HCV infection. 


\section{Incidence of CKD in patients with $\mathrm{HCV}$ infection}

The stages of CKD as defined by the Kidney Disease: Improving Global Outcomes (KDIGO) guidelines range from normal (CKD stage 1) to kidney failure (CKD stage 5) and are described in Table 1 [7]. Until recently, data regarding the prevalence of CKD in patients with hepatitis $\mathrm{C}$ were limited. In HCV-positive patients, the prevalence of low glomerular filtration rate $\left(\mathrm{GFR}<60 \mathrm{ml} / \mathrm{min} / 1.73 \mathrm{~m}^{2}\right)$ is reported to range from 5.1 to $17.2 \%$ [ $\left.\underline{8}-10\right]$, and the prevalence of renal insufficiency (serum creatinine $\leq 1.5 \mathrm{mg} / \mathrm{dl}$ ) is $4.8 \%$ in US veterans [11]. In patients coinfected with HIV and HCV, the unadjusted frequency of low GFR (30-59) ranged from 3.7 to $4 \%$ [12]. Based on the National Kidney Foundation's Kidney Disease Outcomes Quality Initiative (KDOQI) modified guidelines [13], the prevalence of CKD was significantly greater among patients with detectable HCV RNA compared with age-, race- and gender-matched anti-HCV-negative controls $(9.1 \%$ versus $5.1 \% ; P<0.04)$ [14]. According to data from the Chronic Hepatitis Cohort Study, the prevalence of estimated (e)GFR $<80$ $\mathrm{ml} / \mathrm{min} / 1.73 \mathrm{~m}^{2}$ was $33 \%$ and eGFR $<30 \mathrm{ml} / \mathrm{min} / 1.73 \mathrm{~m}^{2}$ was $2 \%$ in patients with $\mathrm{HCV}$ infection, including those with hepatic fibrosis [15].

Table 1. KDIGO 2012 classification of CKD stages

\begin{tabular}{llll} 
GFR category & CKD stage & Description & GFR, ml/min/1.73 m² \\
\hline G1 & 1 & Normal or high & 290 \\
G2 & 2 & Mildly decreased & $60-89$ \\
G3a & $3 a$ & Mildy to moderately decreased & $45-59$ \\
G3b & $3 b$ & Moderately to severely decreased & $30-44$ \\
G4 & 4 & Severely decreased & $15-29$ \\
G5 & 5 & Kidney failure & $<15$
\end{tabular}

Reprinted with permission from KDIGO 2012 Clinical Practice Guideline for the Evaluation and Management of Chronic Kidney Disease by the Kidney Disease: Improving Global Outcomes (KDIGO) CKD Work Group (2013) in Kidney Int Suppl 3:1-150. CKD, chronic kidney disease; GFR, glomerular filtration rate.

The incidence of HCV-associated glomerular disease is low. A Norwegian study found the prevalence of CKD stage 5 due to membranoproliferative glomerular disease to be $0.2 \%$ [16]. Multivariate analysis of data from a large case-control study showed that membranoproliferative glomerulonephritis (MPGN) was more common in patients with HCV infection $(0.36 \%$ versus $0.05 \% ; P<0.0001)$, but not membranous glomerulonephritis $(0.33 \%$ versus $0.19 \% ; P=0.86)[\underline{17}]$.

\section{HCV: a non-traditional risk factor for CKD}

Conventional risk factors for CKD such as ageing, diabetes, hypertension and metabolic syndrome do not fully explain the frequency of CKD in developed countries. In addition to these risk factors, $\mathrm{HCV}$ infection has been implicated as a cause of kidney disease. A metaanalysis of observational studies ( $n=9$ studies; $n=1,947,034$ unique patients) reported a relationship between anti-HCV-positive status and CKD [18]. The estimated adjusted hazard ratio (aHR) for $\mathrm{HCV}$ was 1.43 (95\% CI 1.23, 1.63; $P=0.0001)$ [18]. Significant heterogeneity 
$(P=0.001)$ was noted [18]; thus, additional research is needed to confirm the link between HCV and CKD [18]. A retrospective cohort study $(n=56,488)$ found that patients with HCV infection had a $27 \%$ increased risk of CKD compared with non-HCV-infected patients $(\mathrm{HR}=1.27,95 \% \mathrm{CI} 1.18,1.37)$. In addition, the risk of CKD decreased by $30 \%$ (HR=0.70, $95 \%$ CI $0.55,0.88)$ in patients who had received anti-HCV treatment. HCV-infected patients also had a higher risk of MPGN (HR=2.23, 95\% CI 1.84, 2.71) and cryoglobulinaemia $(\mathrm{HR}=16.91,95 \% \mathrm{CI} 12.00,23.81)$ than uninfected control patients [19].

The relationship between HCV and CKD has also been studied in HIV-HCV coinfection. A meta-analysis of 8 studies $(n=105,462)$ showed a link between HCV infection and reduced GFR among HIV-infected patients (aHR 1.64 HIV-HCV-coinfected patients versus HIVmonoinfected patients; 95\% CI 1.28, 2.0; $P<0.001)[20]$.

The mechanisms underlying the relationship between chronic HCV and CKD are unclear [21]. HCV has also been implicated in the pathogenesis of tubulointerstitial injury [22]. HCVinduced glomerular disease occurs frequently in the context of $\mathrm{HCV}$-associated mixed cryoglobulinaemia (MC). MC represents $60-75 \%$ of all cryoglobulinaemia and is found in connective tissue diseases and infectious or lymphoproliferative disorders. The majority of patients with 'essential' MC are chronically infected with HCV [21].

A large spectrum of glomerular diseases have been associated with chronic HCV infection (Table 2). Type I MPGN with type II MC is most commonly observed in relation to HCV. Less frequent kidney diseases include MPGN without cryoglobulinaemia and membranous nephropathy. Focal segmental glomerulosclerosis, fibrillary or immunotactoid glomerulopathies and thrombotic microangiopathy have also been reported [23]. In addition, tubulo-interstitial nephritis and vasculitis have been associated with HCV. The association between HCV and glomerular disease has been observed in patients with native kidneys, and dual kidney and liver transplantations [21]. The clinical manifestations of HCV-related glomerular disease include nephrotic or nephritic syndrome as well as isolated proteinuria and haematuria and lowered eGFR [21].

Table 2. HCV-associated kidney disease and clinical manifestations

\begin{tabular}{ll}
\hline Kidney disease & Clinical manifestations \\
\hline $\begin{array}{l}\text { Cryoglobulinaemic membranoproliferative glomerulonephritis } \\
\text { Mesangial proliferative glomerulonephritis }\end{array}$ & $\begin{array}{l}\text { Nephritic and/or nephrotic syndrome } \\
\text { Isolated proteinuria and/or haematuria } \\
\text { Isolated proteinuria and/or reduced glomerular filtration rate } \\
\text { Nephrointerstitial nephritis }\end{array}$ \\
$\begin{array}{l}\text { Non-cryoglobulinaemic membranoproliferative glomerulonephritis } \\
\text { Non-cryoglobulinaemic membranous nephropathy }\end{array}$ & $\begin{array}{l}\text { Nephritic and/or nephrotic syndrome } \\
\text { Nephrotic syndrome or isolated proteinuria }\end{array}$ \\
Non-cryoglobulinaemic focal segmental glomerulonephritis & Nephrotic syndrome or isolated proteinuria \\
Immunotactoid glomerulopathy; fibrillary glomerulonephritis & Nephrotic syndrome, isolated proteinuria and/or haematuria \\
Thrombotic microangiopathy & Nephrotic syndrome, isolated proteinuria and/or haematuria
\end{tabular}

Reprinted with permission from Hepatitis $\mathrm{C}$ virus infection, mixed cryoglobulinemia, and kidney disease by Fabrizi F, Plaisier E, Saadoun D, et al. (2013) in Am J Kidney Dis 61:623637. 
HCV appears to play a role in metabolic derangements and accelerated atherosclerosis. Atherosclerosis is a chronic inflammatory disease and, in addition to the 'traditional' factors of atherosclerosis, other 'novel' factors (such as chronic HCV infection) have been suggested. The possible role of an infectious agent in the development of experimental atherosclerosis in rodents was reported more than a century ago [24] and this hypothesis has gained renewed interest recently [25]. It is likely that HCV promotes atherogenesis through several direct and indirect biological mechanisms. HCV RNA sequences have been isolated from carotid plaques [26], suggesting a direct cytopathic effect of the virus on endothelial cells [21]. Promotion of atherogenesis translates into adverse clinical outcomes, as evidenced by the results of a large prospective cohort study $(n=23,665)$ that demonstrated a significantly higher risk of cerebrovascular death in anti-HCV-positive patients than in anti-HCV-negative patients $(2.7 \%$ versus $1.0 \%, P<0.001$; aHR $2.18,95 \%$ CI $1.50,3.16)$ [27].

$\mathrm{HCV}$ infection causes hepatic and systemic inflammation, and hepatic steatosis [3] , which is currently considered an early mediator of atherosclerosis. Hepatic steatosis promotes the development of atherosclerosis through multiple factors including insulin resistance, hypoadiponectinaemia, metabolic syndrome, oxidative stress, hyper-homocysteinaemia and increased synthesis of tumour necrosis factor- $\alpha[\underline{2}, \underline{28}]$. These activities occur independently of other traditional risk factors. There is a well-established association between chronic HCV infection and insulin resistance and diabetes mellitus that persists after adjusting for major risk factors such as older age, obesity and smoking [29].

\section{Treating HCV infection improves renal outcomes in patients with CKD}

The most important clinical manifestation of nephrosclerosis induced by $\mathrm{HCV}$ is reduced eGFR with or without non-nephrotic proteinuria. International guidelines issued by the KDIGO HCV Study Group have already recommended that HCV-infected patients be tested at least annually for proteinuria, haematuria and eGFR to detect possible $\mathrm{HCV}$-associated kidney disease [30]. In addition, patients with CKD should be tested for HCV [30]. The recent evidence on the link between chronic HCV and CKD, as discussed above, increases the strength of these recommendations.

Of note, HCV antiviral therapy significantly improves extrahepatic outcomes in the general population [31] and among patients coinfected with HIV and HCV [32]. A retrospective, population-based study in Taiwan has shown that interferon-based therapy reduces the risk of stroke in diabetic patients with chronic hepatitis $\mathrm{C}$ [31]. Six studies have addressed the impact of interferon-based regimens on the incidence and/or progression of CKD in patients with $\mathrm{HCV}$ infection $[14, \underline{33}-\underline{37}]$. In five of them, multivariate analysis suggested that interferonbased antiviral treatment of $\mathrm{HCV}$ improves per se renal survival [14,33- $\underline{37]}$. The most important evidence on this point comes from three large population-based studies using the Taiwan National Health Insurance Research Database (NHIRD) [33- 35], and similar results have been found in two hospital-based studies from the US [14] and Japan [36]. Although various demographic and clinical parameters were included in the multivariate analyses, an important limitation is that the NHIRD does not contain information regarding virology, for example, the viral genotype, the sustained virological response (SVR) to antiviral therapy and the HCV viral load [33 $\underline{35}$ ]. 
In the direct-acting antiviral (DAA) era, it has also been demonstrated that HCV treatment improves kidney-related outcomes. A study by Khan et al. [38] showed that in patients who achieved SVR ( $n=962)$ after DAA treatment, renal function improved (defined as any increase in GFR) compared with baseline in those with CKD stage 3 and $4-5$ by $10 \%$ ( $\Delta$ GFR from baseline $+5.04 \mathrm{ml} / \mathrm{min}$ ) and $22 \%$ ( $\Delta$ GFR from baseline $+2.42 \mathrm{ml} / \mathrm{min})$, respectively. A total of $n=80$ relapsed (CKD stage $1-5$ ) and improvement in GFR occurred in CKD stage 3 patients who relapsed after DAA treatment ( $\triangle$ GFR from baseline $+9.17 \mathrm{ml} / \mathrm{min})$; achieving SVR was not a significant predictor of GFR improvement $(\mathrm{OR}=0.9,95 \% \mathrm{CI} 0.5,1.7)$ [38]. A retrospective, observational cohort study using the US administrative claims Quintiles/IMS PharMetrics Plus database demonstrated a reduction in the risk of end-stage renal disease (ESRD) following DAA therapy $(n=19,606$, incidence rate ratio [IRR] $=0.86,95 \%$ CI 0.72 , 1.03). The reduced risk persisted when restricted to treated patients who were diagnosed with CKD at baseline $(n=976$, relative risk [RR] $=0.76,95 \%$ CI $0.55,1.04)$ [39].

Theoretically, a randomized, placebo-controlled trial is the ideal design to clarify how antiviral treatment improves extrahepatic outcomes of HCV. On the other hand, critical events commonly take time to develop, because they occur at a low incidence in an average-risk population. A large sample size with a long follow-up would be required; in addition, randomization to placebo can hardly be considered as ethically acceptable nowadays for $\mathrm{HCV}$-infected patients, given that safe and effective drugs for antiviral therapy of HCV are currently available. Cohort and case-control studies are in progress to assess whether the persistent clearance of HCV RNA from serum by DAAs reduces the incidence and/or progression of CKD in the adult general population. In the meantime, all anti-HCV seropositive patients should be screened for the presence of HCV RNA in their serum and HCV-RNA-positive patients should be treated with interferon-free DAA combinations to reduce the incidence and progression of CKD.

Various approaches have been recommended for the treatment of HCV-related glomerular disease, including immunosuppressive therapy and antiviral therapy. Antiviral treatment (interferon alone or interferon plus ribavirin) had been adopted in patients with moderate proteinuria and slow loss of kidney function; however, the number of patients enrolled was low. The available data regarding interferon-based antiviral treatment among patients with $\mathrm{HCV}$ infection suggests renal benefits, including remission of proteinuria and haematuria and improved kidney function as serum HCV RNA becomes undetectable. Interferon-based treatments for HCV-associated glomerular disease have shown substantial limitations. First, the impact of antiviral therapy on long-term kidney disease outcomes remains uncertain. Second, response to interferon-based antiviral therapy may take weeks or months and in the case of rapidly progressing kidney disease, kidney failure can develop before clearance of HCV RNA can be obtained. Third, the clinical benefit in patients who obtained SVR may be transient and/or a dissociation between the antiviral and renal responses can occur. Fourth, interferon- $\alpha$ may exacerbate proteinuria in some patients with underlying glomerular disease and ribavirin use is fraught with the risk of worsening anaemia in patients with reduced eGFR [29].

\section{Treating patients with CKD in the era of HCV DAAs}


Before the era of interferon-free treatment regimens, few $\mathrm{HCV}$-infected patients with renal impairment underwent $\mathrm{HCV}$ treatment due to the toxicity and poor tolerability of the available regimens [39]. According to the Dialysis Outcomes and Practice Patterns Study, an observational study enrolling 49,762 patients on maintenance dialysis in 12 countries between 1996 and 2011, only $48 \mathrm{HCV}$-positive patients (1.0\%) of the 4,589 HCV-positive patients with prescription data were receiving antiviral therapy [40].

However, breakthroughs in the understanding of the HCV life-cycle and the ability to directly interfere with viral replication within hepatocytes have revolutionized the management of $\mathrm{HCV}$. The recent introduction in the market of DAAs offers shorter, interferon-free, welltolerated and highly efficacious curative therapies. An increasing number of DAAs with high potency against HCV are now available. The choice of the appropriate DAA for patients with renal impairment is clearly conditioned by their pharmacokinetics (Figure 1) [41-43].

International guidelines from the US and Europe, currently recommend no dose adjustment of all approved DAAs in patients with mild to moderate renal impairment. However, in patients with severe renal impairment, only three regimens are recommended: elbasvir plus grazoprevir; ombitasvir, paritaprevir (boosted with ritonavir) plus dasabuvir [41, $\underline{42}]$; and the pan-genotypic glecaprevir plus pibrentasvir regimen [42].

Figure 1. Routes of elimination for current DAAs

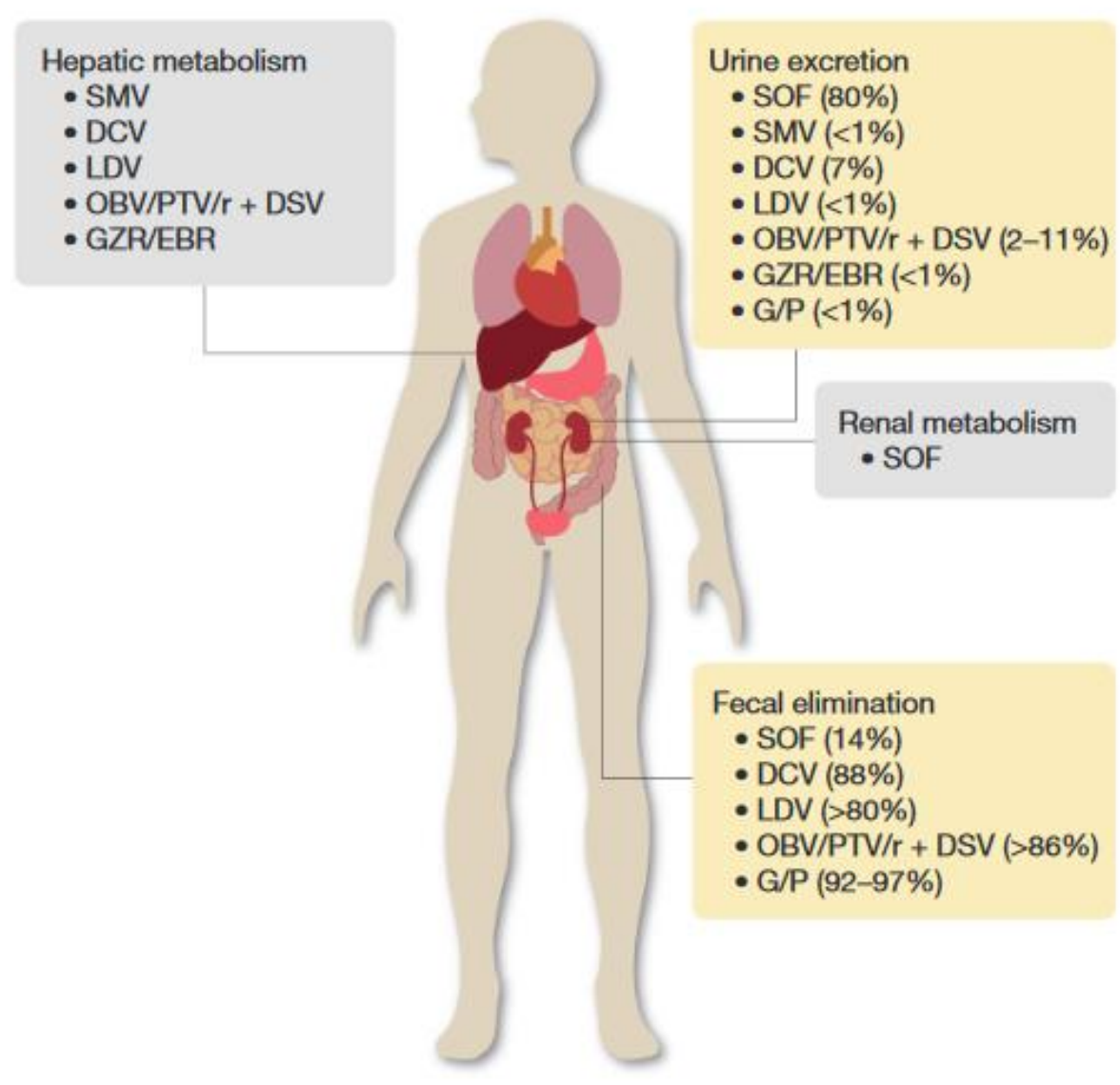

Depiction of the sites of metabolism (liver or renal) and routes of elimination (urine or fecal) of direct-acting antivirals (DAAs) assessed in patients with renal impairment. Glecaprevir undergoes limited secondary metabolism and pibrentasvir is not metabolized. DCV, 
daclatasvir; DSV, dasabuvir; EBR, elbasvir; G, glecaprevir; GZR, grazoprevir; LDV, ledipasvir; OBV, ombitasvir; P, pibrentasvir; PTV, paritaprevir; r, ritonavir; SMV, simeprevir; SOF, sofosbuvir.

Sofosbuvir is approximately $80 \%$ renally excreted, mostly as its dephosphorylation-derived nucleoside metabolite GS-331007. Although sofosbuvir dose adjustments are not required in patients with mild or moderate renal impairment [44], no dose recommendations can be provided for patients with severe renal impairment (that is, eGFR $<30 \mathrm{ml} / \mathrm{min} / 1.73 \mathrm{~m}^{2}$ ) or with ESRD requiring haemodialysis $[41, \underline{42}]$. Ledipasvir is mostly eliminated unchanged in bile, whereas renal excretion is minimal (approximately 1\% of the total); however, ledipasvir is not marketed as a stand-alone drug, being only available in a fixed-dose combination with sofosbuvir. Velpatasvir pharmacokinetics have been studied in uninfected persons with severe renal insufficiency, in whom the increased area under the concentration-time curve (AUC) was not deemed clinically significant: again, given that velpatasvir is marketed in combination with sofosbuvir, its use in these patients is restricted by the latter's disposal profile. Sofosbuvir-based DAA therapy has been evaluated in patients with HCV-associated $\mathrm{MC}$ and glomerular disease. In one report, the SVR rate 12 weeks after the end of treatment (SVR12) was 86\% (6/7) and serious adverse events were uncommon [4]. Renal involvement was established by kidney biopsy in many patients $(71 \%, 5 / 7)[\underline{45}$ ]. Patients who achieved SVR12 experienced an improvement in serum creatinine and a reduction in proteinuria [44]. In another 2016 study on sofosbuvir-based DAA therapy in patients with HCV-associated MC $(n=44)$, four patients had renal involvement (one had renal biopsy showing MPGN with arterial hypertension, one had nephrotic syndrome and two had reduced GFR and proteinuria) [46]. The SVR rate at 12 and 24 weeks was $100 \%$ (44/44); among the four patients with kidney involvement, the patient with MPGN experienced an increase in the GFR up to normal levels, subsiding of proteinuria and normalization of blood pressure. Another individual had complete remission of nephrotic syndrome and discontinuation of albumin and diuretics, and the two remaining patients had a marked improvement of the GFR with protein urine excretion again in the normal range. In the VASCUVALDIC study, sofosbuvir plus ribavirin was administered for 24 weeks in patients with $\mathrm{HCV}$-associated cryoglobulinaemia vasculitis $(n=24)$; five patients had kidney involvement (four had a renal biopsy showing MPGN) [47]. All patients showed persistent viral clearance and $80 \%$ achieved a complete clinical improvement: kidney involvement improved in four out of five (80\%) patients. The median creatinine level was $89 \mu \mathrm{mol} / \mathrm{l}(80-163 \mathrm{SD})$ at baseline and $85 \mu \mathrm{mol} / \mathrm{l}(78-146 \mathrm{SD})$ at week 24 . Median GFR was $77.3 \mathrm{ml} / \mathrm{min} / 1.73 \mathrm{~m}^{2}(44-90 \mathrm{SD})$ at baseline and $66.7 \mathrm{ml} / \mathrm{min} / 1.73 \mathrm{~m}^{2}(48$ $87 \mathrm{SD}$ ) at week 24 . Haematuria occurred in four out of five $(80 \%)$ at diagnosis and disappeared in all cases at week 24 ; daily proteinuria decreased from $1.09 \mathrm{~g}(0.6-2.4 \mathrm{SD})$ to $0.17 \mathrm{~g}(0.07-0.25 \mathrm{SD})$. However, $40 \%$ of patients with renal involvement also received immunosuppressants; thus, the contribution of antiviral therapy (sofosbuvir + ribavirin) in the improvement of kidney disease remains unclear. Other, more recent studies have confirmed the very good impact of another DAA combination of sofosbuvir plus daclatasvir in patients with $\mathrm{HCV}$-associated $\mathrm{MC}$, including restoration of immune tolerance $[\underline{48}, \underline{49}]$. The disappearance of cryoglobulin occurred in $46.1 \%$ of patients (13/24) [49] and further studies are warranted to assess whether the DAAs can reduce the need for corticosteroids and immunosuppressive agents (for example, cyclophosphamide and others).

Daclatasvir is an agent partially metabolized by CYP3A4, which can be safely used in patients with end-stage renal impairment, including those requiring haemodialysis [50]. The HCV DAA simeprevir, undergoes oxidative metabolism by the liver and its renal excretion is negligible [51]. Thus, no dose adjustments are necessary in patients with mild, moderate or 
severe renal impairment (Table 3); however, its safety has not been evaluated when creatinine clearance falls below $30 \mathrm{ml} / \mathrm{min} / 1.73 \mathrm{~m}^{2}$. In addition, given that simeprevir is extensively bound to plasma proteins ( $>99.9 \%$ ), primarily to albumin [52], dialysis is unlikely to result in removal of significant amounts of drug. Some DAAs are still combined with ribavirin in some categories of patients and, owing to potential anaemia adverse events, ribavirin dose adjustments are mandatory in patients with ESRD. It has already been shown that low-dose ribavirin (that is, $200 \mathrm{mg}$ daily, or $200 \mathrm{mg} \times 3$ weekly) is safe and effective in patients with eGFR $<30 \mathrm{ml} / \mathrm{min} / 1.73 \mathrm{~m}^{2}$ [28].

Table 3. Approved and recommended DAA regimens in HCV-infected patients with renal impairment $^{a}$

\begin{tabular}{lll}
\hline Genotype & Approved regimen & Recommended regimen [42] \\
\hline GT1a & OBV/PTV/r + DSV + RBV for 12 weeks; EBR/GZR for 12 weeks; G/P 8-12 weeks & EBR/GZR for 12 weeks; G/P 8-16 weeks \\
GT1b & OBV/PTV/r + DSV for 12 weeks; EBR/GZR for 12 weeks; G/P 8-12 weeks & EBR/GZR for 12 weeks; G/P 8-16 weeks \\
GT2 & G/P 8-12 weeks & G/P 8-16 weeks \\
GT3 & G/P 8-12 weeks & G/P 8-16 weeks \\
GT4 & OBV/PTV/r + RBV for 12 weeks; EBR/GZR for 12 weeks; G/P 8-12 weeks & EBR/GZR for 12 weeks; G/P 8-16 weeks \\
GT5/6 & G/P 8-12 weeks & G/P 8-16 weeks \\
\hline
\end{tabular}

${ }^{a}$ Estimated glomerular filtration rate $<30 \mathrm{ml} / \mathrm{min} / 1.73 \mathrm{~m}^{2}$. DAA, direct-acting antiviral; DSV, dasabuvir; EBR, elbasvir; G, glecaprevir; GT, genotype; GZR, grazoprevir; OBV, ombitasvir; $\mathrm{P}$, pibrentasvir; PTV, paritaprevir; r, ritonavir; RBV, ribavirin.

Three currently available combinations have been specifically evaluated in patients with kidney impairment. The first comprises ombitasvir, paritaprevir (boosted with ritonavir) and dasabuvir: all are excreted essentially into the faeces. Their AUC is mildly increased in patients with severe renal impairment and thus no dose adjustments are necessary in these cases (Table 3). It has been shown that plasma concentrations of these drugs are not substantially affected by dialysis [53]. In the first single-arm, multicentre RUBY-1 trial [54], 20 treatment-naive, non-cirrhotic HCV genotype-1 patients with CKD stage 4 or 5 received ombitasvir, paritaprevir (boosted with ritonavir) and dasabuvir for 12 weeks. The 13 patients with subtype 1a also received ribavirin. All patients completed treatment, although in nine patients, ribavirin had to be stopped because of anaemia. An overall SVR12 of $90 \%$ was achieved, with only one relapsed patient. In the RUBY-II trial, subtype-1a and -4 patients with severe renal impairment or ESRD were treated with ombitasvir, paritaprevir (boosted with ritonavir) and/or dasabuvir without ribavirin for 12 weeks [55]. An overall SVR12 of $94 \%$ (17/18) was achieved, with one patient not completing treatment due to an elective renal transplantation. Real-world studies from Spain and Germany have subsequently confirmed these encouraging clinical trial data. An overall SVR12 rate of $96 \%$ was achieved in 46 patients with genotype 1 or 4 ( $n=17$ with cirrhosis) treated with ombitasvir and paritaprevir (boosted with ritonavir), with or without dasabuvir across nine Spanish centres: only 2/21 had to suspend ribavirin [56]. Real-world data from the German Hepatitis C Registry show a $100 \%$ SVR1 2 rate in 34 patients with moderate to severe renal impairment ( $n=9$ with CKD stage 4 or 5). Of 10 patients who discontinued treatment, five were associated with ribavirin. However, clinically relevant changes in eGFR from baseline to end of treatment did not occur in these patients [57]. 
A second combination comprises coformulated elbasvir plus grazoprevir. Both are partially metabolized by CYP3A4 and the main route of excretion is into faeces, with $<1 \%$ in urine. Both drugs are extensively bound to plasma proteins. No dose adjustments are required in patients with mild, moderate or severe renal impairment, including those on haemodialysis (Table 3). The moderate exposure increase in uninfected individuals with CKD stage 4 is not considered clinically significant. In the C-SURFER study, a large randomized and placebocontrolled study, 224 patients with HCV genotype-1 infection (among which were 179 patients undergoing haemodialysis) received a 12-week course of elbasvir/grazoprevir once a day ( $n=122$, including $6 \%$ with cirrhosis) or placebo. Excluding six patients from the efficacy analysis for non-virological reasons, the SVR12 was 99\% (115/116) [58]. The treatment was also well tolerated, with minor headache, nausea and fatigue being reported in a similar proportion in patients receiving active drugs or placebo. The SVR rate was 98\% (97/99) in the deferred treatment group (that is, those patients who were initially included in the placebo group), according to a modified full analysis set [59].

A third combination is a pan-genotypic regimen consisting of glecaprevir co-formulated with pibrentasvir. The drugs are predominantly eliminated via the biliary-faecal route $(92.1 \%$ and $96.6 \%$ excreted in the faeces, and $0.7 \%$ and $0 \%$ excreted in the urine for glecaprevir and pibrentasvir, respectively) $[\underline{60}, \underline{61}]$. No dose adjustment of glecaprevir/pibrentasvir is needed in patients with any degree of renal impairment including those patients with ESRD with or without haemodialysis $[\underline{62}, \underline{63}]$. In the Phase III clinical trial EXPEDITION-IV, the safety and efficacy of glecaprevir/pibrentasvir was studied in non-cirrhotic or compensated cirrhotic patients with genotype $1-6$ and CKD stage $4-5$ including those on haemodialysis $(n=104)$ [64]. The SVR12 rate was 98\% (102/104); no patient had virological failure. Serious adverse events were reported in $24 \%$ of patients (25/104); however, none were considered by the investigators as related to study treatment. Overall, glecaprevir/pibrentasvir was well tolerated with the most common adverse events ( $\geq 10 \%$ of patients) being pruritus, fatigue and nausea. No patients with grade 3 haemoglobin abnormalities discontinued prematurely and there were no grade $\geq 2$ abnormalities in alanine aminotransferase [64]. An integrated analysis of genotype 1-6-infected patients from 8 Phase II and III clinical trials also demonstrated that, irrespective of the severity of renal impairment, a high SVR12 rate $(97-98 \%, n=2,238)$ was achieved. Neither did the level of renal impairment impact on the safety profile of glecaprevir/pibrentasvir, with similar frequencies and types of adverse events across CKD stages. The frequency of pruritus was higher in CKD stage 4-5 patients, however, these patients do have a higher background rate compared to those with lower CKD stages [65-67]. The safety profile was similar in patients with or without compensated cirrhosis with low rates of drug-related serious adverse events $(<1 \%)$ and adverse events leading to discontinuation $(\leq 4 \%)[\underline{67]}$.

Based on the above considerations, patients with mild to moderate renal impairment (down to eGFR $\geq 30 \mathrm{ml} / \mathrm{min} / 1.73 \mathrm{~m}^{2}$ ) can be treated with all combinations (that is, ledipasvir/sofosbuvir, sofosbuvir/velpatasvir, ritonavir-boosted paritaprevir/ombitasvir plus dasabuvir, elbasvir/grazoprevir, glecaprevir/pibrentasvir, sofosbuvir and daclatasvir or sofosbuvir and simeprevir) without dose adjustments. The general recommendations contained in international guidelines can be safely applied $[\underline{41}, \underline{42}]$. In patients with severe renal dysfunction (eGFR $<30 \mathrm{ml} / \mathrm{min} / 1.73 \mathrm{~m}^{2}$ ), regimens without sofosbuvir are preferred. In the TARGET 2.0 real-world study, a progressive worsening of renal function was reported in patients with severe renal impairment receiving sofosbuvir-based regimens [68]. According to their multivariate analysis, worsening of renal function was more common in patients on sofosbuvir-containing regimens who had eGFR $\leq 45 \mathrm{ml} / \mathrm{min} / 1.73 \mathrm{~m}^{2}$ at baseline (versus eGFR 
$\left.>45 \mathrm{ml} / \mathrm{min} / 1.73 \mathrm{~m}^{2}\right)$, incidence risk ratio $4.71(95 \% \mathrm{CI} 1.85,12.0 ; P<0.001)$. Based on a small number of patients, some studies found that sofosbuvir-based regimens may be effective and relatively safe for individuals with HCV infection and eGFR $<30 \mathrm{ml} / \mathrm{min} / 1.73 \mathrm{~m}^{2}$ in the presence or absence of cirrhosis [69-71]. Further larger-scale prospective studies are needed to determine the optimal combination and duration of DAA therapy in ESRD. In the meantime, sofosbuvir-free regimens should be preferred whenever possible in patients with ESRD.

The European Association for the Study of the Liver (EASL) guidelines for the treatment of $\mathrm{HCV}$ recommend that patients with CKD stage 4 or 5 who are not candidates for kidney transplantation and are infected with HCV genotype 1a should receive paritaprevir coformulated with ritonavir and ombitasvir plus dasabuvir for 12 weeks, or the combination of grazoprevir/elbasvir for 12 weeks, with low-dose $(200 \mathrm{mg} /$ day) ribavirin [41]. The same combinations can be used in similar patients with genotype $1 \mathrm{~b}$, but this time without ribavirin, whereas those with genotype 4 should be treated with paritaprevir co-formulated with ritonavir and ombitasvir, associated with low-dose ribavirin, for 12 weeks or with the fixeddose combination of elbasvir/grazoprevir, without ribavirin [41]. For all of the above, the use of ribavirin in patients in whom the haemoglobin level is $\leq 10 \mathrm{~g} / \mathrm{dl}$ at baseline is discouraged. The American Association for the Study of Liver Disease (AASLD) guidelines, recommend 12 weeks of elbasvir/grazoprevir for genotype-1 and -4 infection and 8-16 weeks of glecaprevir/pibrentasvir for genotype-1-6 infection in patients with CKD stage 4 or 5 [42]. Although clear information on the treatment of $\mathrm{HCV}$ in patients with renal impairment exists, it is possible that many clinicians are not aware of the extrahepatic renal manifestations of HCV (glomerular and extra-glomerular lesions induced by HCV) and these recommendations may not be entirely followed [72]. This potential lack of awareness of guideline recommendations highlights the need for continued medical education by physicians leading to better patient care $[\underline{72}, \underline{73}]$.

\section{DAAs after renal transplant: current issues}

Interferon and ribavirin have been the mainstay of therapy for HCV infection for the past 30 years. However, interferon-containing $\mathrm{HCV}$ regimens were rarely used in the kidney transplant population because they are associated with low efficacy (18-34\%), poor tolerability (drop-out rate of 25-32\%) and high risk of irreversible interferon-induced graft rejection (12.5-51\%) [74]. Antiviral therapy after renal transplant is needed because of several reasons; first, immunosuppressive therapy post renal transplant may have a permissive role on the replication of $\mathrm{HCV}$ with acceleration of liver damage. In addition, the clearance of HCV RNA may prevent some post-transplant complications related to $\mathrm{HCV}$ viraemia such as diabetes mellitus [75], de novo or recurrent $\mathrm{HCV}$-induced glomerular disease [76], chronic allograft nephropathy [77] and higher trough levels of calcineurin inhibitors [78- 20$]$. Recently, it has been shown that DAAs can be safely and effectively used after kidney transplant [81-84]. In a recent study from the HCV-TARGET cohort, 443 post-transplant patients (renal transplant $n=60$, renal and liver transplant $n=36$, liver transplant $n=347$ ) with HCV infection were treated with DAA regimens (87\% genotype 1, 42\% cirrhotic). Patients were treated with ledipasvir/sofosbuvir (85\%), daclatasvir plus sofosbuvir (9\%), or ombitasvir, paritaprevir (boosted with ritonavir), and dasabuvir $(6 \%)$, all with or without ribavirin. The proportion of patients with an eGFR $\leq 30$ was $13 \%$ in renal transplant patients and $6 \%$ in dual transplant patients. Overall SVR12 was 96\% (397/415) with 95\% and 91\% in renal and dual transplant patients, respectively. Treatment was well tolerated with six $(1.4 \%)$ 
episodes of acute rejection during HCV treatment in four patients and after HCV treatment in two patients [85]. In another study, 114 patients (91\% with genotype $1,15 \%$ with compensated cirrhosis) were treated with ledipasvir/sofosbuvir for 12 or 24 weeks and all achieved SVR12 [6]. However, all the patients enrolled in the trial showed at baseline an eGFR of $\geq 40 \mathrm{ml} / \mathrm{min} / 1.73 \mathrm{~m}^{2}$.

A recent case series has raised some concerns about the safety of DAAs after transplant: three solid organ recipients developed focal segmental glomerulosclerosis (documented by kidney biopsy) while on therapy with ledipasvir/sofosbuvir, with $(n=2)$ or without $(n=1)$ ribavirin [87]. The hypotheses for DAA-associated focal segmental glomerulosclerosis includes direct podocyte toxicity, interaction with post-transplant immunosuppressive agents, and an 'immune reconstitution syndrome' [8]. Routine urinalysis monitoring before and during antiviral therapy is strongly recommended.

When kidney transplantation is planned, the indication to treat before or after surgery is debated. Given that HCV-associated liver damage can be accelerated by immunosuppression, treatment before kidney transplantation may be administered without concerns according to the above recommendations.

The advent of DAAs gives the opportunity to obtain HCV RNA clearance in most patients with ESRD before or after renal transplant. However, the subgroup of patients that remains difficult to treat are those with end-stage CKD and decompensated liver disease. To date, no data from controlled clinical trials are available in these patients [89]. Expert opinion is required to guide the management of these patients.

A crucial point now is the timing of HCV therapy in relation to the renal transplant procedure. Important issues for establishing correct timing include the use of living versus deceased donor organs, waitlist time by donor type, policy at centre-level for acceptance of organs from $\mathrm{HCV}$-positive deceased donors and HCV genotype. HCV-infected renal transplant candidates with well compensated liver disease may defer anti-HCV therapy after renal transplant from $\mathrm{HCV}$-positive deceased donors. In fact, many studies have emphasized that renal transplant from HCV-positive donors can lower the time spent on the transplant waiting list [90], and shorter times on the waitlist confer better survival after renal transplant. HCV-positive grafts can expand the donor organ pool as the demand for renal transplants greatly surpasses the current supply in the developed world $[91,92]$.

The availability of highly effective DAA regimens has the potential to expand the pool of kidney donors for $\mathrm{HCV}$-negative patients with end-stage CKD. Rather than remain on the waiting list for an HCV-negative kidney, it would be preferable that the HCV-negative patient with $\mathrm{CKD}$ receive a kidney graft from an $\mathrm{HCV}$-positive donor and receive DAA therapy to prevent or eradicate HCV infection. There are now reports that demonstrate that this strategy is not only feasible, but highly practical $[93,94]$. In the first report, therapy with elbasvir/grazoprevir was initiated on post-transplant day 3 (all recipients were viraemic) and continued for 12 weeks in ten HCV-negative recipients of HCV-positive kidney transplants. All ten patients in this pilot study achieved SVR12 and had a functioning graft after the conclusion of DAA therapy [93]. The success of this strategy has recently been confirmed in a series of ten $\mathrm{HCV}$-negative patients who received $\mathrm{HCV}$-positive kidney grafts. All patients received a single dose of elbasvir/grazoprevir pre-transplant followed by 12 weeks of DAA therapy post-transplant, at which time they were shown to have achieved SVR12 [94]. 


\section{Conclusions}

The recent availability of HCV DAAs promises to make profound changes in the management of HCV infection in patients with kidney disease. Safe and effective combinations of DAAs are now available for patients with CKD stage 4 or 5 and HCV genotype- 1 or -4 infection. In addition, with the approval of the first pan-genotypic regimen, glecaprevir/pibrentasvir, suitable in patients with any degree of renal impairment, the previous unmet need in patients with genotypes 2, 3, 5 and 6 no longer exists. Considering chronic $\mathrm{HCV}$ is a risk factor for CKD, all patients with CKD of any stage, irrespective of the occurrence of liver damage, should receive HCV treatment. Importantly, achievement of SVR with DAA treatment has been shown to be associated with improved overall survival in the short term. Whether these short-term benefits translate into improved long-term renal outcomes remains to be confirmed.

\section{Acknowledgements}

Medical Editing support was provided by Gillian Patman of Medical Expressions (Manchester, UK), funded by AbbVie.

\section{Disclosure statement}

FF has received consultancies, advisory board fees or speaker's fees from AbbVie, and Merck Sharp \& Dohme. FN is an advisor for Gilead, AbbVie and Merck, and has received research grants from Gilead and AbbVie. MB is an employee of AbbVie and may hold stock or options. PC received consulting and lecturing fees from AbbVie, AstraZeneca, Bristol-Myers Squibb, Gilead, GlaxoSmithKline, Janssen, Merck Sharp \& Dohme, Roche, Servier and Vifor. PC has received grants from CNRS, INSERM, Université Pierre et Marie Curie, ANRS and WHO.

\section{References}

1. WHO. Global hepatitis report, 2017. (Accessed December 2017.) Available from http://www.who.int/hepatitis/publications/global-hepatitis-report2017/en/

2. Negro F, Forton D, Craxi A, Sulkowski MS, Feld JJ, Manns MP. Extrahepatic morbidity and mortality of chronic hepatitis C. Gastroenterology 2015; 149:1345-1360. Medline doi:10.1053/j.gastro.2015.08.035

3. Adinolfi LE, Zampino R, Restivo L, et al. Chronic hepatitis $\mathrm{C}$ virus infection and atherosclerosis: clinical impact and mechanisms. World J Gastroenterol 2014; 20:3410-3417. Medline doi:10.3748/wjg.v20.i13.3410

4. McHutchison JG, Ware JE, Bayliss MS, et al. The effects of interferon alpha-2b in combination with ribavirin on health related quality of life and work productivity. $J$ Hepatol 2001; 34:140-147. Medline doi:10.1016/S0168-8278(00)00026-X

5. Younossi ZM, Stepanova M, Afdhal N, et al. Improvement of health-related quality of life and work productivity in chronic hepatitis $\mathrm{C}$ patients with early and advanced fibrosis treated with ledipasvir and sofosbuvir. J Hepatol 2015; 63:337-345. Medline

doi:10.1016/j.jhep.2015.03.014 
6. Levey AS, Coresh J. Chronic kidney disease. Lancet 2012; 379:165-180. Medline doi:10.1016/S0140-6736(11)60178-5

7. Kidney Disease: Improving Global Outcomes (KDIGO) CKD Work Group. KDIGO 2012 Clinical Practice Guideline for the Evaluation and Management of Chronic Kidney Disease. Kidney Int Suppl 2013; 3:1-150.

8. Tsui JI, Vittinghoff E, Shlipak MG, et al. Association of hepatitis C seropositivity with increased risk for developing end-stage renal disease. Arch Intern Med 2007; 167:1271-1276. Medline doi:10.1001/archinte.167.12.1271

9. Moe SM, Pampalone AJ, Ofner S, Rosenman M, Teal E, Hui SL. Association of hepatitis C virus infection with prevalence and development of kidney disease. Am J Kidney Dis 2008;

51:885-892. Medline doi:10.1053/j.ajkd.2008.03.009

10. Asrani SK, Buchanan P, Pinsky B, Rey LR, Schnitzler M, Kanwal F. Lack of association between hepatitis C infection and chronic kidney disease. Clin Gastroenterol Hepatol 2010; 8:79-84. Medline doi:10.1016/j.cgh.2009.08.031

11. Dalrymple LS, Koepsell T, Sampson J, et al. Hepatitis C virus infection and the prevalence of renal insufficiency. Clin J Am Soc Nephrol 2007; 2:715-721. Medline doi:10.2215/CJN.00470107

12. Lucas GM, Jing Y, Sulkowski M, et al. Hepatitis C viremia and the risk of chronic kidney disease in HIV-infected individuals. J Infect Dis 2013; 208:1240-1249. Medline doi:10.1093/infdis/jit373

13. National Kidney Foundation. KDOQI Clinical Practice Guideline for Hemodialysis Adequacy: 2015 update. Am J Kidney Dis 2015; 66:884-930. Medline

doi:10.1053/j.ajkd.2015.07.015

14. Satapathy SK, Lingisetty CS, Williams S. Higher prevalence of chronic kidney disease and shorter renal survival in patients with chronic hepatitis $\mathrm{C}$ virus infection. Hepatol Int 2012; 6:369-378. Medline doi:10.1007/s12072-011-9284-9

15. Moorman AC, Tong X, Spradling PR, et al. Prevalence of renal impairment and associated conditions among HCV-infected persons in the Chronic Hepatitis Cohort Study (CHeCS). Dig Dis Sci 2016; 61:2087-2093. Medline doi:10.1007/s10620-016-4199-x 16. Kristiansen MG, Gutteberg TJ, Mortensen L, Berg LK, Goll R, Florholmen J. Clinical outcomes in a prospective study of community-acquired hepatitis $\mathrm{C}$ virus infection in Northern Norway. Scand J Gastroenterol 2010; 45:746-751. Medline doi:10.3109/00365521003690699

17. El-Serag HB, Hampel H, Yeh C, Rabeneck L. Extrahepatic manifestations of hepatitis C among United States male veterans. Hepatology 2002; 36:1439-1445. Medline doi:10.1002/hep.1840360621

18. Fabrizi F, Verdesca S, Messa P, Martin P. Hepatitis C virus infection increases the risk of developing chronic kidney disease: a systematic review and meta-analysis. Dig Dis Sci 2015; 60:3801-3813. Medline doi:10.1007/s10620-015-3801-y

19. Park H, Chen C, Wang W, Henry L, Cook RL, Nelson DR. Chronic hepatitis C increases the risk of chronic kidney disease (CKD) while effective HCV treatment decreases the incidence of CKD. Hepatology 2017; doi:10.1002/hep.29505. Medline

20. Fabrizi F, Dixit V, Martin P, Messa P. Hepatitis C virus increases the risk of kidney disease among HIV-positive patients: systematic review and meta-analysis. J Med Virol 2016; 88:487-497. Medline doi:10.1002/jmv.24353

21. Fabrizi F, Plaisier E, Saadoun D, Martin P, Messa P, Cacoub P. Hepatitis C virus infection, mixed cryoglobulinemia, and kidney disease. Am J Kidney Dis 2013; 61:623-637. Medline doi:10.1053/j.ajkd.2012.08.040

22. Kasuno K, Ono T, Matsumori A, et al. Hepatitis C virus-associated tubulointerstitial injury. Am J Kidney Dis 2003; 41:767-775. Medline doi:10.1016/S0272-6386(03)00024-6 
23. Fabrizi F, Colucci P, Ponticelli C, Locatelli F. Kidney and liver involvement in cryoglobulinemia. Semin Nephrol 2002; 22:309-318. Medline

24. Gilbert A, Lion G. [Experimental infectious arteritis]. C R Hebd Seances Soc Biol Fil 1889; 41:583-584. [French.]

25. Stassen FR, Vainas T, Bruggeman CA. Infection and atherosclerosis. An alternative view on an outdated hypothesis. Pharmacol Rep 2008; 60:85-92. Medline

26. Boddi M, Abbate R, Chellini B, et al. Hepatitis C virus RNA localization in human carotid plaques. J Clin Virol 2010; 47:72-75. Medline doi:10.1016/j.jcv.2009.10.005

27. Lee $\mathrm{MH}$, Yang HI, Wang $\mathrm{CH}$, et al. Hepatitis $\mathrm{C}$ virus infection and increased risk of cerebrovascular disease. Stroke 2010; 41:2894-2900. Medline

doi:10.1161/STROKEAHA.110.598136

28. Voulgaris T, Sevastianos VA. Atherosclerosis as extrahepatic manifestation of chronic infection with hepatitis C virus. Hepat Res Treat 2016; 2016:7629318 Medline doi: $10.1155 / 2016 / 7629318$

29. Gill K, Ghazinian H, Manch R, Gish R. Hepatitis C virus as a systemic disease: reaching beyond the liver. Hepatol Int 2016; 10:415-423. Medline doi:10.1007/s12072-015-9684-3 30. Kidney Disease: Improving Global Outcomes (KDIGO). KDIGO clinical practice guidelines for the prevention, diagnosis, evaluation, and treatment of hepatitis $\mathrm{C}$ in chronic kidney disease. Kidney Int Suppl 2008; 109:S1-S99.

31. Hsu CS, Kao JH, Chao YC, et al. Interferon-based therapy reduces risk of stroke in chronic hepatitis $\mathrm{C}$ patients: a population-based cohort study in Taiwan. Aliment Pharmacol Ther 2013; 38:415-423. Medline doi:10.1111/apt.12391

32. Berenguer J, Rodriguez E, Miralles P, et al. Sustained virological response to interferon plus ribavirin reduces non-liver-related mortality in patients coinfected with HIV and hepatitis C virus. Clin Infect Dis 2012; 55:728-736. Medline doi:10.1093/cid/cis500

33. Hsu YC, Ho HJ, Huang YT, et al. Association between antiviral treatment and extrahepatic outcomes in patients with hepatitis C virus infection. Gut 2015; 64:495-503. Medline doi:10.1136/gutjnl-2014-308163

34. Chen YC, Hwang SJ, Li CY, Wu CP, Lin LC. A Taiwanese nationwide cohort study shows interferon-based therapy for chronic hepatitis $\mathrm{C}$ reduces the risk of chronic kidney disease. Medicine (Baltimore) 2015; 94:e1334 Medline doi:10.1097/MD.0000000000001334 35. Hsu YC, Lin JT, Ho HJ, et al. Antiviral treatment for hepatitis $\mathrm{C}$ virus infection is associated with improved renal and cardiovascular outcomes in diabetic patients. Hepatology 2014; 59:1293-1302. Medline doi:10.1002/hep.26892

36. Arase Y, Suzuki F, Kawamura Y, et al. Development rate of chronic kidney disease in hepatitis $C$ virus patients with advanced fibrosis after interferon therapy. Hepatol Res 2011; 41:946-954. Medline doi:10.1111/j.1872-034X.2011.00845.x

37. Leone S, Prosperi M, Costarelli S, et al. Incidence and predictors of cardiovascular disease, chronic kidney disease, and diabetes in HIV/HCV-coinfected patients who achieved sustained virological response. Eur J Clin Microbiol Infect Dis 2016; 35:1511-1520. Medline doi:10.1007/s10096-016-2692-y

38. Khan M, Asrani SK, Jennings L, Modi AA. Receiving directly acting antivirals (DAAs) for hepatitis $\mathrm{C}$ improves renal function in patients with CKD regardless of SVR. Hepatology 2017; 66:829A

39. Singer AW, Osinusi AO, Brainard DM, Telep L, Chokkalingam AP. Risk of end stage renal disease in hepatitis $\mathrm{C}$ patients following completion of direct-acting antiviral therapy: a retrospective cohort study. Hepatology 2017; 66:519A

40. Goodkin DA, Bieber B, Gillespie B, Robinson BM, Jadoul M. Hepatitis C infection is very rarely treated among hemodialysis patients. Am J Nephrol 2013; 38:405-412. Medline doi:10.1159/000355615 
41. European Association for the Study of the Liver (EASL). EASL recommendations on treatment of hepatitis C 2016. J Hepatol 2017; 66:153-194. Medline

doi:10.1016/j.jhep.2016.09.001

42. AASLD and IDSA. HCV guidance: recommendations for testing, managing, and treating hepatitis C. 2018. (Updated 24 May 2018. Accessed June 2018.) Available from http://www.hcvguidelines.org/

43. Cacoub P, Desbois AC, Isnard-Bagnis C, Rocatello D, Ferri C. Hepatitis C virus infection and chronic kidney disease: time for reappraisal. J Hepatol 2016; 65:S82-S94. Medline doi:10.1016/j.jhep.2016.06.011

44. Gane EJ, Robson RA, Bonacini M, et al. Safety, anti-viral efficacy and pharmacokinetics (PK) of sofosbuvir (SOF) in patients with severe renal impairment. Hepatology 2014; 60:133A

45. Sise ME, Bloom AK, Wisocky J, et al. Treatment of hepatitis C virus-associated mixed cryoglobulinemia with direct-acting antiviral agents. Hepatology 2016; 63:408-417. Medline doi:10.1002/hep.28297

46. Gragnani L, Visentini M, Fognani E, et al. Prospective study of guideline-tailored therapy with direct-acting antivirals for hepatitis $\mathrm{C}$ virus-associated mixed cryoglobulinemia.

Hepatology 2016; 64:1473-1482. Medline doi:10.1002/hep.28753

47. Saadoun D, Thibault V, Si Ahmed SN, et al. Sofosbuvir plus ribavirin for hepatitis C virus-associated cryoglobulinaemia vasculitis: VASCUVALDIC study. Ann Rheum Dis 2016; 75:1777-1782. Medline doi:10.1136/annrheumdis-2015-208339

48. Saadoun D, Pol S, Ferfar Y, et al. Efficacy and safety of sofosbuvir plus daclatasvir for treatment of HCV-associated cryoglobulinemia vasculitis. Gastroenterology 2017; 153:4952.e5. Medline doi:10.1053/j.gastro.2017.03.006

49. Comarmond C, Garrido M, Pol S, et al. Direct-acting antiviral therapy restores immune tolerance to patients with hepatitis $\mathrm{C}$ virus-induced cryoglobulinemia vasculitis.

Gastroenterology 2017; 152:2052-2062.e2. Medline doi:10.1053/j.gastro.2017.02.037

50. Garimella T, Wang R, Luo WL, et al. Single-dose pharmacokinetics and safety of daclatasvir in subjects with renal function impairment. Antivir Ther 2015; 20:535-543. Medline doi:10.3851/IMP2941

51. Ouwerkerk-Mahadevan S, Beumont-Mauviel M, Mortier S, et al. Evaluation of the pharmacokinetics and renal excretion of simeprevir in subjects with renal impairment. Drugs

$R D$ 2015; 15:261-270. Medline doi:10.1007/s40268-015-0101-0

52. National Center for Biotechnology Information. PubChem Compound Database.

Simeprevir. (Accessed November 2017.) Available from

https://pubchem.ncbi.nlm.nih.gov/compound/24873435

53. Shuster DL, Menon RM, Ding B, et al. Ombitasvir, paritaprevir, ritonavir, dasabuvir and ribavirin pharmacokinetics in $\mathrm{HCV}$-infected subjects with chronic kidney disease stage 4 (severe renal impairment) or stage 5 (end-stage renal disease). Hepatology 2016; 64:975A 54. Pockros PJ, Reddy KR, Mantry PS, et al. Efficacy of direct-acting antiviral combination for patients with HCV genotype 1 infection and severe renal impairment or end-stage renal disease. Gastroenterology 2016; 150:1590-1598. Medline doi:10.1053/j.gastro.2016.02.078 55. Gane EJ, Solà R, Cohen E, et al. RUBY-II: efficacy and safety of a ribavirin-free ombitasvir/paritaprevir/ritonavir \pm dasabuvir regimen in patients with severe renal impairment or end-stage renal disease and HCV genotypes 1a or 4 infection. Hepatology 2016; 64:470A471A.

56. Muñoz-Gómez R, Rincon D, Ahumada A, et al. Therapy with ombitasvir/paritaprevir/ritonavir plus dasabuvir is effective and safe for the treatment of genotypes 1 and 4 hepatitis $\mathrm{C}$ virus (HCV) infection in patients with severe renal impairment: a multicentre experience. J Viral Hepat 2017; 24:464-471. Medline doi:10.1111/jvh.12664 
57. Welzel TM, Hinrichsen H, Sarrazin C, et al. Real-world experience with the all-oral, interferon-free regimen of ombitasvir/paritaprevir/ritonavir and dasabuvir for the treatment of chronic hepatitis C virus infection in the German Hepatitis C Registry. J Viral Hepat 2017; 24:840-849. Medline doi:10.1111/jvh.12708

58. Roth D, Nelson DR, Bruchfeld A, et al. Grazoprevir plus elbasvir in treatment-naive and treatment-experienced patients with hepatitis $C$ virus genotype 1 infection and stage 4-5 chronic kidney disease (the C-SURFER study): a combination Phase 3 study. Lancet 2015; 386:1537-1545. Medline doi:10.1016/S0140-6736(15)00349-9

59. Bruchfeld A, Roth D, Martin P, et al. Elbasvir plus grazoprevir in patients with hepatitis C virus infection and stage 4-5 chronic kidney disease: clinical, virological, and health-related quality-of-life outcomes from a Phase 3, multicentre, randomised, double-blind, placebocontrolled trial. Lancet Gastroenterol Hepatol 2017; 2:585-594. Medline doi:10.1016/S2468$\underline{1253(17) 30116-4}$

60. National Center for Biotechnology Information. PubChem Compound Database.

Glecaprevir. (Accessed November 2017.) Available from

https://pubchem.ncbi.nlm.nih.gov/compound/66828839

61. National Center for Biotechnology Information. PubChem Compound Database.

Pibrentasvir. (Accessed November 2017.) Available from

https://pubchem.ncbi.nlm.nih.gov/compound/58031952

62. Kosloski MP, Dutta S, Zhao W, et al. Pharmacokinetics, safety, and tolerability of next generation direct acting antivirials ABT-493 and ABT-530 in subjects with renal impairment. J Hepatol 2016; 64:S405-S406.

63. Kosloski MP, Dutta S, Zhao W, et al. Hemodialysis does not affect the pharmacokinetics of glecaprevir (ABT-493) or pibrentasvir (ABT-530). J Hepatol 2016; 64:421A

64. Gane E, Lawitz E, Pugatch D, et al. Glecaprevir and pibrentasvir in patients with HCV and severe renal impairment. $N$ Engl J Med 2017; 377:1448-1455. Medline doi:10.1056/NEJMoa1704053

65. Khanna D, Singal A, Kalra OP. Comparison of cutaneous manifestations in chronic kidney disease with or without dialysis. Postgrad Med J 2010; 86:641-647. Medline doi:10.1136/pgmj.2009.095745

66. Min JW, Kim SH, Kim YO, et al. Comparison of uremic pruritus between patients undergoing hemodialysis and peritoneal dialysis. Kidney Res Clin Pract 2016; 35:107-113. Medline doi:10.1016/j.krcp.2016.02.002

67. Pol S, Pockros P, Pugatch D, et al. Safety and efficacy of glecaprevir/pibrentasvir in adults with chronic hepatitis $C$ virus infection genotype 1-6 as a function of chronic kidney disease stage. J Hepatol 2017; 66:S738 doi:10.1016/S0168-8278(17)31967-0

68. Saxena V, Koraishy FM, Sise ME, et al. Safety and efficacy of sofosbuvir-containing regimens in hepatitis $C$ infected patients with impaired renal function. Liver Int 2016; 36:807816. Medline doi:10.1111/liv.13102

69. Hundemer GL, Sise ME, Wisocky J, et al. Use of sofosbuvir-based direct-acting antiviral therapy for hepatitis $\mathrm{C}$ viral infection in patients with severe renal insufficiency. Infect Dis (Lond) 2015; 47:924-929. Medline doi:10.3109/23744235.2015.1078908

70. Bhamidimarri KR, Czul F, Peyton A, et al. Safety, efficacy and tolerability of half-dose sofosbuvir plus simeprevir in treatment of hepatitis $C$ in patients with end stage renal disease. J Hepatol 2015; 63:763-765. Medline doi:10.1016/j.jhep.2015.06.004

71. Choudhary NS, Kumar A, Bodh V, et al. Efficacy and safety of sofosbuvir-based regimens in chronic hepatitis C patients on dialysis. Indian J Gastroenterol 2017; 36:113-116. $\underline{\text { Medline doi:10.1007/s12664-017-0735-7 }}$ 
72. Ramos-Casals M, Zignego AL, Ferri C, et al. Evidence-based recommendations on the management of extrahepatic manifestations of chronic hepatitis $\mathrm{C}$ virus infection. $J$ Hepatol 2017; 66:1282-1299. Medline doi:10.1016/j.jhep.2017.02.010

73. Ferri C, Ramos-Casals M, Zignego AL, et al. International diagnostic guidelines for patients with $\mathrm{HCV}$-related extrahepatic manifestations. A multidisciplinary expert statement. Autoimmun Rev 2016; 15:1145-1160. Medline doi:10.1016/j.autrev.2016.09.006

74. Fabrizi F, Penatti A, Messa P, Martin P. Treatment of hepatitis C after kidney transplant: a pooled analysis of observational studies. J Med Virol 2014; 86:933-940. Medline doi:10.1002/jmv.23919

75. Gürsoy M, Koksal R, Karavelioglu D, et al. Pretransplantation alpha-interferon therapy and the effect of hepatitis $\mathrm{C}$ virus infection on kidney allograft recipients. Transplant Proc 2000; 32:580-582. Medline doi:10.1016/S0041-1345(00)00898-8

76. Cruzado JM, Casanovas-Taltavull T, Torras J, Baliellas C, Gil-Vernet S, Grinyo JM. Pretransplant interferon prevents hepatitis $\mathrm{C}$ virus-associated glomerulonephritis in renal allografts by HCV-RNA clearance. Am J Transplant 2003; 3:357-360. Medline doi:10.1034/j.1600-6143.2003.00057.x

77. Mahmoud IM, Elhabashi AF, Elsawy E, El-Husseini AA, Sheha GE, Sobh MA. The impact of hepatitis $\mathrm{C}$ virus viremia on renal graft and patient survival: a 9-year prospective study. Am J Kidney Dis 2004; 43:131-139. Medline doi:10.1053/j.ajkd.2003.09.018 78. Wolffenbüttel L, Poli DD, Manfro RC, Goncalves LF. Cyclosporine pharmacokinetics in anti-HCV+ patients. Clin Transplant 2004; 18:654-660. Medline doi:10.1111/j.13990012.2004.00256.x

79. Fabrizi F, Messa P, Martin P, Takkouche B. Hepatitis C virus infection and posttransplant diabetes mellitus among renal transplant patients: a meta-analysis. Int J Artif Organs 2008; 31:675-682. Medline doi:10.1177/039139880803100801

80. Guitard J, Rostaing L, Kamar N. New-onset diabetes and nephropathy after renal transplantation. Contrib Nephrol 2011; 170:247-255. Medline doi:10.1159/000325778 81. Kamar N, Marion O, Rostaing L, et al. Efficacy and safety of sofosbuvir-based antiviral therapy to treat hepatitis C virus infection after kidney transplantation. Am J Transplant 2016; 16:1474-1479. Medline doi:10.1111/ajt.13518

82. Sawinski D, Kaur N, Ajeti A, et al. Successful treatment of hepatitis C in renal transplant recipients with direct-acting antiviral agents. Am J Transplant 2016; 16:1588-1595. Medline doi:10.1111/ajt.13620

83. Lin MV, Sise ME, Pavlakis M, et al. Efficacy and safety of direct acting antivirals in kidney transplant recipients with chronic hepatitis C virus infection. PLoS One 2016; 11:e0158431 Medline doi:10.1371/journal.pone.0158431

84. Colombo M, Aghemo A, Liu H, et al. Treatment with ledipasvir-sofosbuvir for 12 or 24 weeks in kidney transplant recipients with chronic hepatitis $C$ virus genotype 1 or 4 infection: a randomized trial. Ann Intern Med 2017; 166:109-117. Medline doi:10.7326/M16-1205 85. Saxena V, Khungar V, Verna EC, et al. Safety and efficacy of current direct-acting antiviral regimens in kidney and liver transplant recipients with hepatitis C: results from the HCV-TARGET study. Hepatology 2017; 66:1090-1101. Medline doi:10.1002/hep.29258 86. Colombo M, Aghemo A, Liu H, et al. Treatment with ledipasvir-sofosbuvir for 12 or 24 weeks in kidney transplant recipients with chronic hepatitis $C$ virus genotype 1 or 4 infection: a randomized trial. Ann Intern Med 2017; 166:109-117. Medline doi:10.7326/M16-1205 87. Hogan JJ, Lim MA, Palmer MB, Bloom RD, Chung RT, Sise ME. Development of proteinuria and focal segmental glomerulosclerosis during direct-acting antiviral therapy for hepatitis C virus infection. Hepatology 2017; 66:658-660. Medline doi:10.1002/hep.29125 88. Sise ME, Wisocky J, Rosales IA, et al. Lupus-like immune complex-mediated glomerulonephritis in patients with hepatitis $\mathrm{C}$ virus infection treated with oral, interferon- 
free, direct-acting antiviral therapy. Kidney Int Rep 2016; 1:135-143. Medline doi:10.1016/j.ekir.2016.06.006

89. Mücke MM, Mücke VT, Lange CM, et al. Managing hepatitis C in patients with the complications of cirrhosis. Liver Int 2017; 37:19-25. Medline

90. Scalea JR, Barth RN, Munivenkatappa R, et al. Shorter waitlist times and improved graft survivals are observed in patients who accept hepatitis $C$ virus+ renal allografts.

Transplantation 2015; 99:1192-1196. Medline doi:10.1097/TP.0000000000000479

91. Kucirka LM, Singer AL, Ros RL, Montgomery RA, Dagher NN, Segev DL.

Underutilization of hepatitis C-positive kidneys for hepatitis C-positive recipients. Am J

Transplant 2010; 10:1238-1246. Medline doi:10.1111/j.1600-6143.2010.03091.x

92. Gallegos-Orozco JF, Kim R, Thiesset HF, et al. Early results of pilot study using hepatitis $\mathrm{C}$ virus (HCV) positive kidneys to transplant $\mathrm{HCV}$ infected patients with end-stage renal disease allowing for successful interferon-free direct acting antiviral therapy after transplantation. Cureus 2016; 8:e890 Medline

93. Goldberg DS, Abt PL, Blumberg EA, et al. Trial of transplantation of HCV-infected kidneys into uninfected recipients. N Engl J Med 2017; 376:2394-2395. Medline doi:10.1056/NEJMc1705221

94. Durand CM, Bowring MG, Brown DM, et al. Direct-acting antiviral prophylaxis in kidney transplantation from hepatitis $\mathrm{C}$ virus-infected donors to noninfected recipients: an open-label nonrandomized trial. Ann Intern Med 2018; 168:533-540. Medline

doi:10.7326/M17-2871 